\title{
Construindo a "Picada": colonização florestal, capital social e obrigações comunitárias em Picada Felipe Essig, Travesseiro/RS
}

\author{
Building the "Picada": forest colonization, social capital and community obligations in Picada Felipe Essig,
} Travesseiro, state of Rio Grande do Sul, Brazil

\section{Eduardo Relly}

Freie Universität Berlin - Berlim - Alemanha

\begin{abstract}
Resumo: A picada teuto-brasileira se constituiu historicamente a partir das colonizações florestais realizadas por comunidades oriundas da Europa de língua alemã ou de seus descendentes diretos. Neste sentido, o discurso sobre os assentamentos rurais teuto-brasileiros assumiu na historiografia uma dimensão que realçava os aspectos autossuficientes, comunitários e isolados destas mesmas comunidades diante da sociedade brasileira. Este artigo propõe repensar estas assertivas colocando em causa esta perspectiva a partir da teoria de capital social em contexto pré-modernos. Utiliza-se a Picada Felipe Essig/RS como estudo de caso para a verificação empírica dos pressupostos teóricos acima expostos. Logo, a picada teuto-brasileira aparece como uma expressão cultural atualizada do contexto de aldeia centro-europeia e surge como uma forma de organização social que embora mostre inúmeros conflitos em seu interior, apresenta, ao mesmo tempo, vetores de cooperação e institucionalização comunitária que pretenderam diminuir as complexidades do novo ambiente colonizado.
\end{abstract}

Palavras-chave: Imigração alemã. Picada. Capital social.

\begin{abstract}
The German-Brazilian Picada was formed from the forest colonizations carried out by communities originated from the German-speaking Europe or from their direct descendants. In this sense, the discourse over the German-Brazilian settlements assumed in historiography a dimension that highlighted the aspects of self-sufficiency, community life and isolation of these communities before the bigger Brazilian society. This paper proposes to rethink these assumptions questioning them according to social capital theory in pre-modern contexts. Picada Felipe Essig, state of Rio Grande do Sul, Brazil, is the place where empirical observations took place in order to verify the theory's assumptions. Therefore, the German-Brazilian Picada surges as an updated cultural expression connected to the context of the former central-European villages and as a form of social organization which - though the existence of several conflicts in its intern social development - shows at the same time cooperation vectors and community institutionalization that aimed at preventing the complexities of the new colonized environment.
\end{abstract}

Keywords: German immigration. Picada. Social capital. 


\section{Introdução}

Embebidos numa tradição de vida comunitária experimentada na aldeia europeia e amparados por laços significativos de capital social (BLICKLE, 1998, p. 12), os povos germânicos constituíram uma sociedade nova e original no contexto brasileiro, a picada teuto-brasileira. A comunidade rural formada pelos teuto-brasileiros foi comumente pensada em termos de autonomia, cooperação e desenvolvimento de aparelhagem sócio-comunitários; subscrevemonos a esta interpretação sem, no entanto, objetivarmos a recriação mascarada da mitologia do colono modernizador, tampouco de levantarmos as velhas bandeiras do isolamento geográfico e das comunidades idílicas que marcaram o discurso historiográfico dos memorialistas e, também, uma certa forma de memória social (TRAMONTINI, 2003, p. 43).

Ao mesmo tempo em que afirma a importância de uma história específica e anterior à imigração para o Brasil - sobretudo a necessidade por parte de historiadores brasileiros de adentrarem no estudo das comunidades camponesas do mundo de língua alemã até o século XIX -, este artigo se propõe a discutir mais especificamente a inventividade, as adaptações, as obrigações, as relações pessoais e a relativa autonomia das comunidades para resolverem seus problemas internos e externos. O enfoque direcionado à picada teuto-brasileira ressalta os movimentos autônomos dessa comunidade humana, ou seja, aquilo que ela fez ou tentou fazer por conta própria. Neste sentido, argumenta-se que o capital social foi o combustível de todas essas iniciativas, bem como estruturas de poder no interior das comunidades. Analisaremos a comunidade de Picada Felipe Essig, atualmente localizada no município de Travesseiro/RS.

\section{A picada teuto-brasileira: aproximações na bibliografia}

Mesmo a despeito da presença das instituições estatais e do auxílio e vantagens oferecidas pela colonização privada, o colonizador teuto-brasileiro esteve, em maior ou menor grau, numa relativa dependência de seus talentos (VOGT, 2006, p. 128). Tramontini (2003, p. 140-141), inclusive, com sua perspicaz problematização da organização social dos imigrantes e dos relatos do isolamento, enquistamento e fraternidade étnica, entende que não é possível "recusar a influência do isolamento geográfico e demográfico na organização do mundo colonial, muito menos o 'isolamento' como caracterização da solidão do imigrante". Tramontini não negou as dificuldades iniciais e a autonomia dos imigrantes, contudo propôs a relativização deste relato que embasa tradicionalmente a história da imigração alemã ao Brasil.

Neste sentido, não há contradição em compreender a picada teuto-brasileira como uma comunidade provida de significativos estoques de capital social e munida de espírito societário com as perspectivas de Tramontini (2003) e Witt (2007), autores que ressaltam de modo competente o aspecto conflituoso da imigração alemã nas suas dimensões internas e externas. Falar de capacidade organizativa, de confiança e cooperação não significa atribuir à Picada Felipe Essig, por exemplo, qualquer caráter idílico ou de irrealidade. As relações de poder existiram no interior da comunidade, as rivalidades ocorreram; porém, em muitos casos, elas foram mediadas pelas estruturas comunitárias, pelo capital social, e, em último caso, pela justiça extraterritorial estatal (VON MÜHLEN, 2017, p. 313).

Para entender a picada teuto-brasileira é preciso notar que os indivíduos que as formaram vinham, com exceção, talvez, dos imigrantes de origem urbana e de outras regiões específicas, de contextos não plenamente capitalistas. Estavam geralmente na metade do caminho entre as estruturas feudais e o capitalismo (EDDIE, 2013, p. 68). Nas Alemanhas do século XIX, os processos de liberação camponesa (Bauerbefreiung) e de dissolução dos recursos econômicos utilizados de modo comunal (Gemeinheitstheilung) atravessaram aquele tempo e preparam a transição de uma economia marcadamente cooperativa para uma de ordem 
liberal-burguesa-capitalista (SCHNEIDER, 2010, p. 191-192). Os imigrantes germânicos que chegam ao Brasil a partir do século XIX são, majoritariamente, filhos históricos destes movimentos.

Neste sentido, é forçoso notar que as características da picada teuto-brasileira giravam inevitavelmente em torno de um processo de negociação entre o mundo social de origem e o ambiente receptor sul-brasileiro (RADÜNZ, 2007, p. 125). Sob o ponto de vista desta análise, percebe-se que as interpretações da história e das demais ciências sociais sobre o sucesso do empreendimento imigratório alemão orbitam ao redor de causalidades econômicas, políticas e culturais que são quase que totalmente explicadas a partir das realidades americanas. Isto significa dizer que o conhecimento sócio-histórico da picada não pode prescindir das condições sociais existentes na Europa de origem, pois a realidade brasileira faz parte somente de uma dimensão - ainda que talvez a mais relevante - do problema de pesquisa (GANS, 2004, p. 19)

O caminho escolhido para uma aproximação compreensiva ao universo da sociedade teutobrasileira é a análise do significado social da picada teuto-brasileira. A picada foi o modelo de desenvolvimento predominante das comunidades germânicas no sul do Brasil. É possível de ser verificado na Argentina, Uruguai, Paraguai e também no Chile (ainda que em menor escala). Ela podia também ser chamada regionalmente de Linha, Travessão ou Lajeado; também é possível encontrar a designação alemã Schneisse ou a forma alemanizada Pikade (DREHER, 2008, p. 33).

Neste sentido, o termo "picada" adquiriu no Rio Grande do Sul do século XIX acepções diversas, que se definem na medida e no lugar onde se encontravam os agentes sociais. Para o colonizador proprietário de terras, a picada era um mero acesso aos prazos coloniais de sua propriedade e que foram brevemente vendidos para os imigrantes ou seus descendentes. Para as populações espoliadas das matas de ervais, as picadas da colonização eram uma forma e um símbolo de opressão e destruição do seu modo de vida. Para o imigrante/migrante a picada se constituiu em sua casa, seu destino nas matas do Brasil meridional.

Martin Dreher (2005, p. 15-16) entende que o modelo social da picada fora espalhado a partir da experiência da colônia de São Leopoldo e rumou para o restante das regiões ocupadas por alemães ou seus descendentes. Este processo de exportação de um tipo específico de organização social pôde ser verificado durante todo o processo de imigração. De tal modo, para Dreher a picada que nada mais era do que uma

[...] trilha de acesso a uma propriedade, passou a ser, em pouco tempo, orientadora e organizadora de vida comunal, geograficamente identificável. Era unidade humana na qual se encontrava templo [...], a escola (tradição trazida pelos imigrantes e que teria importância fundamental para 0 desenvolvimento do Brasil meridional), o cemitério (espaço de reverência a mortos e de preservação de memória comunal), a residência do professor ou do padre/pastor, o salão de festas comunitárias (também designado de sociedade ou clube). Cada picada abrigava uma casa comercial, entreposto para o qual eram vendidos os excedentes de produção e através do qual se adquiriam bens não produzidos na comunidade.

Do ponto de vista da dinâmica interna da picada, passa-se à visão relacional das comunidades alemãs no Brasil. Com efeito, Marcos Witt (2008, p. 23) e Marcos Tramontini (2003, p. 142) embasam essa perspectiva. Embora não tenham buscado uma definição da picada teuto-brasileira, os autores entendem as comunidades alemãs menos por meio de sua autonomia e auto-suficiência do que através de contatos e relações estabelecidas com as autoridades e a sociedade brasileira. Estes autores estão preocupados em entender as formas de inserção política dos teuto-brasileiros como condição de sua americanização, cidadania e estabelecimento de sua organização social.

O formato de colonização alemã baseado na pequena propriedade e na cultura de gestão autônoma e auto-suficiente, cujas origens sociais remontavam à presença de instituições comunais na Europa, fez com que toda propriedade rural ou núcleo familiar pertencesse a algum tipo de núcleo 
comunitário. Na Alemanha, tal núcleo era chamado de Marken e compreendia basicamente os associados que podiam explorar determinados recursos comunais como florestas, lagos, turfeiras, etc (BRAKENSIEK, 1991, p. 2-3). No caso da picada teuto-brasileira, a comunidade rural era por sua vez formada por escola, igreja, cemitério, associações recreativo-desportivas e estruturas comerciais. Ser teuto-brasileiro numa picada indicava, portanto, a possibilidade da fruição de uma espécie de rede de proteção social básica, materializada nos aparelhos sociais acima descritos e nas relações de vizinhança.

Desta forma, o significado sociológico da picada teuto-brasileira por consequência se aproxima de uma noção de autogerenciamento de recursos, trabalho e investimentos. Desta forma, Dreher (2008, p. 34) completa que a estrutura institucional da picada

[...] seguindo a forma de sua instalação, buscou autonomia, auto-suficiência, autoadministração e autogerenciamento, pois o quotidiano girava em torno de quatro eixos fundamentais: religião, escola, agricultura, arte e diversões. a) Em todas as picadas foram reservadas áreas de terras para a construção da capela, de cemitério, moradia do pastor ou vigário. Cada capela tinha sua diretoria, que envolvia todos os moradores em torno da capela. Construções e manutenção das mesmas eram atribuição das diretorias que envolviam os moradores das picadas. Não se contratavam serviços externos. b) Fato semelhante aconteceu com a escola, que também tinha sua área de terras e sua diretoria escolar, a quem competia contratar professor, acompanhar seus trabalhos, garantir sua remuneração. Assim como a igreja a escola fazia parte da atividade comunal. c) Característica particular da picada é a atividade econômica de produção e consumo. Toda família era proprietária de uma 'colônia', na qual se ensaiava autosuficiência.

\section{Picada Felipe Essig e o modelo de picada: cooperações, mas também conflitos}

Picada Felipe Essig localiza-se no interior do município de Travesseiro/RS, situado na região nordeste do estado brasileiro do Rio Grande do Sul. O município de Travesseiro foi emancipado em 20/03/1992, originado de Arroio do Meio, que, por sua vez, foi criado em 28/11/1934 desmembrado do município de Lajeado/RS. A Picada Felipe Essig dista aproximadamente 120 quilômetros da capital do Estado, Porto Alegre (IBGE, 2013).

A localidade é banhada pelo rio Forqueta, o principal afluente do rio Taquari, pertencendo, portanto, à Bacia Hidrográfica Taquari-Antas e está incluída geopoliticamente na região do Vale do Taquari (Kreutz, 2008, p. 52).

A ocupação do território de Picada Felipe Essig pelos colonizadores de origem germânica ocorreu inicialmente a partir da metade da década de 1870. O primeiro morador da comunidade teria sido Felipe Essig, cujo nome originou a própria denominação da localidade. Ele teria adquirido suas terras do empreendedor Frederico Adolfo Moog, residente em São Leopoldo, e, em 1875, teria supostamente iniciado suas atividades nas terras de sua propriedade (CONRAD, 2002, p. 34)

Picada Felipe Essig não era uma colônia oficial onde houvesse o papel centralizador de um "grande" administrador ou diretor capaz, num primeiro momento, de fazer intermediações políticas de mesma natureza como aquelas feitas nas velhas e oficiais colônias da província. Também não era uma colônia de propriedade de empresas; pessoas físicas foram os colonizadores deste espaço.

É possível inferir que essa área era parcialmente desassistida pelo poder público, pelo menos num primeiro momento - até o advento do século XX. O que pode corroborar essa assertiva é o fato de que do outro lado do rio Forqueta, margem oposta à Picada Essig que é atravessada pelo rio citado, ou seja, na Terra dos Bastos, nas atuais localidades de Picada Mai e Tamanduá em Marques de Souza/RS, estabeleceram-se alguns integrantes remanescentes do movimento Mucker com a finalidade de se afastar das autoridades (MÜLLER, 1998, p. 35).

Pode-se imaginar, por conseguinte, que nas colônias privadas e mais distantes, os colonos e suas instituições tinham um maior grau de resolução e liberdade no que concerne à solução dos seus problemas, facilitando iniciativas autônomas dos 
moradores (WEIMER, 2004, p. 113). Em Picada Felipe Essig, esse parece ser o padrão dadas as condições de ocupação inicial.

$\mathrm{Na}$ impossibilidade de reviver o padrão de assentamento europeu no Brasil, logo nos primeiros anos da colonização florestal, se desenvolveu em Picada Felipe Essig a vizinhança como um sistema de mútua ajuda, trocas de experiências e reforço de capital social. Tal característica espacial das picadas teuto-brasileiras, Jean Roche (1969, p. 209-211) chamou de "habitat em fileiras".

Apesar das restrições impostas pelo regime de propriedade privada na formação de núcleos reconhecidamente comunitários para os padrões europeus de referência (em termos espaciais), notase que as residências das picadas permaneceram na parte dianteira da propriedade, próxima à passagem da estrada. Esta configuração tinha uma função que ia para além do simples aspecto econômico, pois criava espaços de aproximação e socialização. Mas, aproximação e sociabilidade também geravam efeitos econômicos através do capital social. Em Picada Felipe Essig, este padrão de assentamento se verifica até os dias correntes (Figura 1).

Figura 1: Mapa da comunidade de Picada Felipe Essig realizado através das metodologias do Diagnóstico Rural Participativo do trabalho de Paulo Conrad. Observa-se nitidamente, em pleno século $X X I$, que as habitações se encontram nas bordas da estrada, caracterizando a ordenação espacial do sistema de vizinhança.

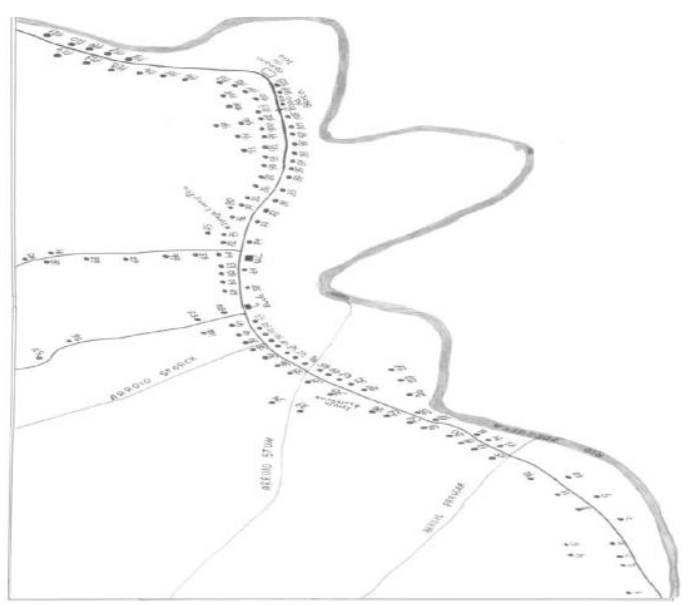

Fonte: CONRAD, 2002, p. 28
A estruturação da picada enquanto organização social exigia uma série de compromissos e obrigações por parte dos seus usuários. Com maior ou menor grau de comprometimento, em geral, a manutenção das estruturas comunitárias era um tema que tocava à grande maioria dos moradores. As obrigações da espacialidade da vizinhança atuavam nesse sentido, pois "ser vizinho" gerava direitos e deveres entre os moradores da picada. Este "direito informal" criava também conflitos no interior da comunidade, pois sempre haveria de existir alguém que se julgasse não atendido pelas expectativas de troca comunitária. A coação ao exercício dos direitos e deveres de vizinhança se dava na base do "o que os vizinhos vão pensar?". O direito da picada, a lei da terra, forma de territorialização dos teuto-brasileiros nas matas do Brasil meridional, era um poderoso agente de controle social.

Desta forma, o capital social presente na vida comunitária de Picada Felipe Essig foi de vital importância para a superação dos riscos que toda nova colonização florestal apresentava. O capital social foi capaz de suprir demandas que o poder público não foi capaz de fornecer em alguns momentos. Chama a atenção que a presença do poder público em todo o processo de imigração é marcada pela ambiguidade. Se por um lado sua presença diminuiu os impactos do processo de americanização dos colonos (doação de terras, transporte, alimentos, hospedaria, ferramentas, sementes, etc.), de outro produziu dificuldades que quase arruinaram o fluxo de imigrantes para o Brasil e, especialmente, para a província. Descumprimento contratual, negligência com os núcleos diretamente administrados, e, principalmente, os desastrosos procedimentos de medição dos lotes - o que infernizou e quase inviabilizou a vida comunitária de muitas colônias - foram elementos que demonstram a falta de qualidade dos gestores e instituições públicas naquele momento. O Reskript von der Heydt de 1859, emitido pelo ministro do comércio prussiano, talvez possa ser considerado o corolário das fragilidades do poder público brasileiro, já que expôs negativamente 
o país na comunidade internacional (CUNHA, 2006, p. 293).

Assim ocorre que em 1887, os colonos de Marques de Souza e de Picada Felipe Essig (incluindo o próprio Felipe Essig, o pioneiro da região) passaram a discutir a substituição do prédio da escola que atendia a comunidade, pois esta já se encontrava velha e pequena para as necessidades locais. As crônicas do pastor Saenger, embasadas nos registros do primeiro professor da comunidade, Louis B. Buss, afirmam que mesmo antes da interferência do pastor Christian Kleikamp de Conventos, esta escola existia sem que houvesse participação direta de nenhuma Igreja institucional (MÜLLER, 1998, p. 37). O próprio professor, Louis B. Buss, não era pastor ou membro de alguma instituição; era simplesmente colono.

O interessante é que neste mesmo relato, a comunidade aparece antes da sua fundamentação jurídica efetivada e auxiliada pelo Pastor Kleikamp no ano de 1887 (MÜLLER, 1998, p. 37). Ou seja, alguma comunidade existia sem que houvesse uma formalização da mesma. Está-se diante de uma organização comunitária baseada em capital social e na transferência de modelos de vida da Europa central para as florestas do sul do Brasil, pois na ausência de oferta dos serviços almejados pela população, os próprios moradores resolveram se organizar enquanto comunidade e buscar soluções para o problema da instrução dos seus jovens.

Em 1917¹, o Intendente Municipal João Batista de Melo ao se referir sobre a instrução do município nas áreas coloniais diz impressionado que "é justo acrescentar que logo que se forma qualquer núcleo de moradores, por pequeno que seja, os colonos promovem a creação de uma aula, embora com sacrifícios pecuniários para manterem os professores". Neste sentido, observa-se o peso das obrigações comunitárias a que estavam submetidos os colonos.

Embora muitas vezes arregimentados pelos pastores que os ameaçavam com maldições espirituais, os colonos doavam seus recursos

${ }^{1}$ Relatório apresentado pelo intendente João Batista de Melo ao Conselho Municipal na sessão de 15 de outubro de 1917. Arquivo Histórico Municipal de Lajeado. (terrenos, comida, dinheiro, trabalho, etc.), para a satisfação de demandas sociais da comunidade em que viviam. Mesmo frequentemente coagidos e contrariados, o que se observa é que existia um substrato cultural que os impelia a participar da construção da sua comunidade. O pastor Saenger (MÜLLER, 1998, p. 38) dizia, por exemplo, do comportamento do fundador de Picada Felipe Essig quando da construção do templo evangélico-luterano de Marques de Souza inaugurado em 1889: "As pedras para a obra foram fornecidas a um preço bem acessível por Philipp Essig. Este vivia murmurando, insatisfeito, mas era muito fiel e com visão de progresso. Ele ainda doou, no dia 12 de fevereiro de 1890, dois cálices e a pia batismal”.

Em 1915, Picada Felipe Essig recebeu 1:272\$250 em conta de "Melhoramentos Materiaes" investidos pelo poder público. Neste mesmo ano, o colono Alfredo Fuchs deduziu a importância de 1:554\$750 de seu imposto agrícola por ter realizado serviços na comunidade. A arrecadação está inscrita no "Emprego das importâncias arrecadadas pela emissão de apólices destinadas a melhoramentos materiaes" da Intendência Municipal. O poder público não esteve ausente do processo de construção da picada teuto-brasileira, havendo, como nesse caso, até uma simbiose. No entanto, é revelador que a Intendência Municipal procedesse dessa maneira no sentido de prover melhoramentos públicos a partir do trabalho dos moradores, o que sugere a tibieza de suas possibilidades operacionais.

O capital social em Picada Felipe Essig veio acompanhado das clássicas instituições que perfazem a teoria do capital social: associações esportivas, clubes de canto, comunidade religiosa de base comunitária, escolas, etc (PUTNAM, 2006, p. 183).

Podemos citar entre as iniciativas ${ }^{3}$ dos moradores de Felipe Essig a fundação em 1911 da Sociedade de Cantores Concórdia, fundada por sete

\footnotetext{
${ }^{2}$ Relatório apresentado pelo intendente João Batista de Melo ao Conselho Municipal na sessão de 15 de outubro de 1916. Arquivo Histórico Municipal de Lajeado.

${ }^{3}$ Cabe lembrar o papel do Deutschum na formalização e condução das mais diversas formas de associativismo ligadas às populações germânicas no Brasil (RADÜNZ, 2007, p. 121).
} 
membros iniciais "que [...] imprimiu vida cultural a comunidade, através da realização dos bailes de corais, sua participação em cultos, festas e enterros de membros da comunidade" (CONRAD, 2002, p. 12). A ênfase na formação musical dos indivíduos contribuiu positivamente para a formação de conjuntos musicais que animavam festas e bailes, promovendo o encontro e interação das pessoas. Nesse sentido, a comunidade tinha uma tradição de formação de competentes regentes de corais, que orientavam os grupos formados em Picada Felipe Essig e outras localidades.

A formação oficializada da comunidade era frequentemente uma formalização de uma vida social e comunitária anterior. Mas ela podia ser também uma forma de demarcação de espaços de privilégio, influência e poder sobre os outros membros da picada. É flagrante, por exemplo, que as condições financeiras da família Essig pareçam muito superiores em relação aos demais membros da comunidade. Contribuir para a comunidade gerava prestígio com o pastor e dava visibilidade social. Junto com as formas de distinção social que existiam no interior das comunidades, houve, contudo, no decorrer da história de Picada Felipe Essig eventos que geraram instabilidade social. Como a picada teuto-brasileira era e é habitada por pessoas de carne e osso e não por santos abnegados, rivalidades e preconceitos muitas vezes não tiveram chance de serem contornados por vias institucionais formais (justiça estatal, comunidade religiosa, diretorias, etc.) e informais (relações de amizade, confiança, arbitramento de questões entre vizinhos, etc.).

Em 1895, no calor da Revolução Federalista, momento difícil para todas as comunidades que viviam às margens do rio Forqueta, uma briga de vizinhos ceifou a vida de Felipe Essig, o conhecido fundador da comunidade homônima. O pastor Saenger embasado nas informações de atas, lembretes e memória social afirmava que "um tal de Johannes de Potter, residente, com sua família, na outra margem do Forqueta, distante de templo, escola e cemitério, assassinou a tiros, o ativo membro da comunidade Philipp Essig, com quem estava inimizado" (MÜLLER, 1998, p. 36).

A rivalidade de Felipe Essig e Johannes de Potter pode ser imaginada pelo fato de que os dois dispunham de barcas para fazer o transbordo de carroças, pessoas e mercadorias para Marques de Souza/RS, na época Nova Berlim da Forqueta. Eram concorrentes de longa data, pois desde 1883 Johannes de Potter oferecia esse serviço aos moradores e, a partir de 1890, Felipe Essig entrou no negócio oferecendo o serviço de outra barca (CONRAD, 2002, p. 17).

O que chama ainda mais a atenção do observador é o destino do corpo de Felipe Essig. Este foi enterrado num cemitério particular, encravado nas suas próprias terras; não foi sepultado - como de costume - no cemitério ao lado do templo da comunidade religiosa a qual ele pertencia, qual seja, Nova Berlim da Forqueta.

Em título de comparação, outro fundador membro da mesma comunidade, Georg Relly, ascendente direto deste autor, faleceu em 1893 por meio de um disparo de arma de fogo causado por seu próprio descuido. Ao contrário de Felipe Essig, seu corpo foi sepultado no cemitério comunitário.

Os fatos sugerem uma indagação: por que Felipe Essig não foi enterrado na comunidade religiosa que ele mesmo ajudou a fundar? Pode-se elencar uma série de motivos que exigem uma pesquisa mais acurada. Mas depreende-se, até por razões lógicas, que algum tipo de desentendimento possa ter ocorrido entre o "ativo membro da comunidade" (MÜLLER, 1998, p. 36) e a instituição que ele ajudou a estabelecer.

Outro episódio trágico nas imediações foi a morte por linchamento dos remanescentes Mucker de Terra dos Bastos (atual localidade de Tamanduá, Marques de Souza/RS) e Picada May (Marques de Souza/RS), acusados do assassinato de uma mulher (DICKIE, 2006, p. 342). Este acontecimento marcou boa parte do médio e baixo Forqueta, representando um ato de intolerância com a diversidade de experiência religiosa protagonizada pelo movimento iniciado no morro do Ferrabraz. 
O pastor Saenger em suas crônicas lembra que a comunidade de Tamanduá era fortemente influenciada pelos Mucker e que eles "ainda estavam convictos da messianidade de Jakobine Maurer". O mesmo pastor comenta que "em 1897, formaram-se grupos de execução, com aproximadamente trezentos homens, em todo o município" (MÜLLER, 1998, p. 46). Saenger comenta que não houve participação dos membros da comunidade de Nova Berlim da Forqueta, mas "muitos homens e jovens da comunidade subiram até Picada May e participaram do linchamento dos Mucker" (MÜLLER, 1998, p. 39). É provável que indivíduos de Picada Felipe Essig também tenham tomado parte no crime.

Estes dois eventos são associados a momentos de crises pontuais que acompanharam a história do Rio Grande do Sul. Eles não têm profundidade histórica para caracterizar o desenvolvimento de Picada Felipe Essig como um todo, a despeito dos padrões religiosos tidos como "aceitos" pela comunidade no episódio do extermínio Mucker.

Os acontecimentos trágicos servem como evidências de que a picada teuto-brasileira, apesar de seu capital social e sentido societário, não era um lugar de pensamento monolítico e privado de conflitos sociais. Como mais um exemplo disso, em 1926 houve a divisão da comunidade em dois Sínodos Evangélicos, o IECLB (Igreja Evangélica de Confissão Luterana do Brasil) e o IELB (Igreja Evangélica Luterana do Brasil), também conhecido como Missouri (CONRAD, 2002, p. 12). Dreher (2006, p. 334), a respeito da religiosidade dos imigrantes alemães, é definitivo: "não houve identidade coletiva religiosa. Ela é obra de intelectualidade que buscou enquadrar as comunidades de imigrantes dentro de um ideal a ser alcançado".

Ainda que os conflitos tenham marcado Picada Felipe Essig de maneira concreta, a picada teutobrasileira pode ser considerada uma importante ferramenta de administração de riscos públicos nos primeiros cinquenta anos de colonização. Através do capital social, das obrigações societárias e do comportamento previsível dos agentes sociais que perfaziam a comunidade, muitos dos riscos e demandas públicas puderam ser satisfeitas com maior ou menor sucesso.

Em primeiro lugar, a sobrevivência física. Experientes ou não, todo início de colonização florestal apresentava seus desafios. Apesar do privilégio de ser alvo de uma política governamental de ocupação das terras ditas devolutas e de ter assegurada sua condição de proprietário - algo que foi negado aos nacionais - é possível entrever dificuldades no contato inicial com as matas. As crônicas do pastor Saenger comentam que "a Terra dos Bastos foi, na região, a única colônia onde se construiu uma casa para os imigrantes, onde podiam ser obtidos todos os utensílios agrícolas" (MÜLLER, 1998, p. 45). De resto, é possível supor que em outras colônias auxílios não foram prestados de uma maneira mais incisiva. Na outra margem do Forqueta, as colonizações, como já caracterizadas, foram realizadas por meio da venda de lotes por pessoas físicas, normalmente pequenos e médios empreendedores.

Entre 1916 e 1920, nos registros de batismo ${ }^{4}$ da Evangelische Immanuel Gemeinde oitenta e quatro batismos foram registrados, uma média de aproximadamente 17 batizados ao ano. Na década de 1910, pelo menos em Picada Felipe Essig o crescimento demográfico era considerável, ainda que haja a necessidade de se considerar a mortalidade infantil, risco que não foi possível de ser sanado a partir das estruturas comunitárias, mas que também não prejudicou o crescimento demográfico. Mesmo com essa ressalva, Dacanal (1992, p. 274), que entende o imigrante como um privilegiado, observa uma continuidade histórica do regime alimentar prénatal e pós-natal das áreas de minifúndio no sentido de se observar a qualidade e satisfação do mesmo.

Associado à sobrevivência física, as taxas de natalidade e a produção econômica de Picada Felipe Essig revelam a satisfação dos componentes da nutrição humana já nos primeiros anos de

\footnotetext{
4 Livro de contabilidade e registro de admissões da Evangelische Immanuelgemeinde de Picada Felipe Essig. Acervo da Comunidade Evangélica de Confissão Luterana de Marques de Souza/RS.
} 
colonização da área. A colônia visava sua autossuficiência, porém não podia descuidar de atender futuramente o mercado, seja para pagar dívidas relativas à terra, seja para o crescimento do patrimônio familiar. De toda forma, a agricultura com fins de subsistência foi o principal motor da produção econômica nos primeiros anos de ocupação do território. Associado a isso, havia o consórcio de criação e as habilidades artesanais desenvolvidas ou tradicionalmente praticadas pelas famílias que lhes serviam de complementação e diversificação produtiva (CONRAD, 2002, p. 16). Os pastores também não comentam sobre a fome, ainda que ressaltem dificuldades (roubos de animais, dinheiro, etc.) no período da Revolução Federalista (MÜLLER, 1998, p. 35).

Levando em consideração o problema da moradia, haja vista que somente nas Terras dos Bastos havia alguma estrutura de atendimento às demandas iniciais dos colonizadores, é de se notar que essa necessidade foi atendida satisfatoriamente num período mais avançado. Em 1912, o intendente municipal João Batista de Melo $^{5}$ se considerava satisfeito pelo o que acontecia "nas diversas linhas coloniaes em que quase todos os moradores têm construído casas de moradia, confortáveis, de bons materiaes".

Duas vilas (espaços de concentração de serviços profissionais, educacionais, sociais e espirituais no mundo teuto-brasileiro) atenderam a comunidade de Felipe Essig com mais intensidade: Marques de Souza/RS (Nova Berlim da Forqueta até 1916) e a vila da comunidade de Três Saltos Baixo, no atual município de Travesseiro/RS. Dependendo da distância do lote a estas respectivas vilas o colono se dirigia para aquela que the fosse mais próxima. Alguns usavam Três Saltos Baixo e outros usavam Marques de Souza - vila mais estabelecida, haja vista que já havia virado distrito de Lajeado em 1916 como referência. Ambas as localidades são e foram majoritariamente evangélica-luteranas.

\footnotetext{
${ }^{5}$ Relatório apresentado pelo intendente João Batista de Melo ao Conselho Municipal na sessão de 15 de outubro de 1912. Arquivo Histórico Municipal de Lajeado.
}

Na Picada Felipe Essig existe um trecho de aglutinação de residências e instalações, porém em termos de importância ela não competia com estas duas outras localidades. Mas mesmo assim, havia casas comerciais e serviços especializados que atendiam a comunidade. O que pode ter atrapalhado a formação de uma vila no sentido espacial do termo foi a ausência de interconexões com outras picadas, fato motivado em grande parte pela geografia do local. Três Saltos Baixo fazia esse papel, pois conectava a estrada geral que marca a paisagem de Picada Essig com a Picada São João, Barra do Fão e as localidades altas de Três Saltos Médio e Três Saltos Alto, além da zona italiana de Nova Bréscia, um pouco mais além.

As vilas eram espaços fundamentais, pois na colonização florestal teuto-brasileira muitos serviços públicos eram débeis. Nas vilas viviam os comerciantes de venda que estabeleciam redes de contatos muito maiores daquela vivida normalmente pelos colonos ocupados em agricultura. Na ausência de estradas satisfatórias, os comerciantes locais criaram circuitos comerciais importantes. Ele era parte indelével do sistema colonial e um fornecedor de crédito na localidade. Ademais, na vila havia a Igreja, o salão comunitário, o cemitério, serviços variados de artesanato e as escolas para as crianças.

Seyferth (1974, p. 93) ao comentar sobre a integração entre a vila e o lote colonial - ela se reporta à colonização oficial (provincial) do vale do Itajaí-Mirim em Santa Catarina, sendo esta uma fundamental diferença no caso aqui estudado, pois esta "vila" a que ela se refere centralizava serviços públicos (saúde, administrativos, etc) profissionalizados e oficiais, que eram administrados pela província, estruturas inexistentes em Picada Felipe Essig - diz que

[...] a divisão das terras, as necessidades religiosas, problemas de ordem legal, o comércio, são levados a efeito ao nível da vila e não da pequena propriedade rural. Até mesmo os interesses comuns, a cooperação entre os vizinhos e os trabalhos comunais são resolvidos na vila. A colônia e a vila formam uma unidade impossível de separar. 
E assim, em Picada Felipe Essig, as estruturas comunitárias surgem concomitante às necessidades primeiras dos colonos. Eles sabiam que havia um grande trabalho a ser feito pela frente e que necessitavam da cooperação de todos para o seu próprio crescimento. Para aprender técnicas e cultivos nos Kalender que circulavam pela área colonial era necessário saber ler; para fazer bons negócios e não ser enganado pelo vendedor das terras ou pelo comerciante da venda - sempre houve oportunismo - era preciso saber calcular. Só a comunidade podia prestar essa estrutura. Mesmo no período do arroteamento inicial, quando a infraestrutura era muito precária, era comum que um colono se dispusesse a ensinar as crianças em sua choupana ou no de outrem. E assim também ocorria com o culto religioso, presidido pelo pastor-colono ou padre-colono, que, pelo menos, na ausência de estruturas ainda construídas e de sacerdotes, confortava as almas que receavam de sua distância com Deus (DREHER, 2006, p. 327).

Por isso, não é de todo surpreendente que em 1887 a escola em Marques de Souza já fosse considerada velha, precária e pequena demais (MÜLLER, 1998, p. 37). E tudo isso sem o concurso de pastores ordenados ou ligados ao Sínodo. Também não espanta o fato de que antes da escola evangélica-luterana existir em Picada Felipe Essig, aulas eram dadas para as crianças nas dependências do salão de baile da casa comercial Khol (CONRAD, 2002, p. 14).

\section{Considerações finais}

A americanização dos povos de origem alemã no Brasil gerou um movimento de duplo sentido no campo da organização social. Eles sofreram as imposições do ambiente brasileiro (social e ecológico), porém usaram do repertório cultural de suas origens. No campo, em decorrência disso, nasceu uma nova sociedade, a picada teutobrasileira.

Os colonos agiam de modo comunitário impelidos por suas tradições e pelos riscos que os rondavam. Era preciso alguma organização e a picada teuto-brasileira foi seu resultado, pois "diante de novos problemas que requerem solução coletiva, homens e mulheres de toda a parte vão buscar soluções no seu próprio passado" (PUTNAM, 2006, p. 184). O capital social não é uma propriedade da sociedade ou um atributo social que pressupõe comunidades idílicas guiadas pelos princípios absolutos da justiça, bondade e solidariedade. As pessoas buscam a satisfação dos seus interesses, porém acreditam que podem buscar algum auxílio, por exemplo, com seus vizinhos, mas, ao mesmo tempo, sabem que essa ajuda terá de ser retribuída em algum outro momento. Aquele que desrespeitar o fundamento da previsibilidade pode ser excluído desse sistema de cooperação, com consequências funestas para o seu próprio crescimento. O agir coletivo, portanto, se faz sob o interesse do indivíduo, mas seus efeitos escapam a ele e inundam a comunidade produzindo efeitos públicos.

Os colonos e colonas parecem ter percebido que dadas as condições em que se encontravam o seu sucesso também dependia relativamente do sucesso dos outros. Afinal de contas, para escoar a madeira ou a produção era preciso passar pela frente do trecho de picada dos vizinhos. Para aprender sobre as madeiras, os cultivos, as enchentes, etc. era necessário um local de reunião. E quanto mais gente, melhor: mais troca de experiências, mais cooperação, mais possibilidades de acordos em atividades que, por alguma razão, não podiam ser feitas adequadamente de modo individual ou unicamente familiar.

Tudo na imigração alemã parece acontecer muito rápido. Desmatar, plantar, estradas, escola, igreja e cemitério. São as estruturas da comunidade que dão impulso aos colonos. E mesmo na mais recôndita mata, a possibilidade da organização de uma comunidade estruturada, por mais "primitiva" que fosse, sempre foi uma grande vantagem, com ou sem a presença da Igreja institucional (católica ou evangélica-luterana) ou qualquer outra agremiação típica da Germanidade (Deutschtum). 
Com esse relato, desde o início se evidenciou o apelo de comunidade em Picada Felipe Essig. Festas como o Kerb (comemorado no terceiro final de semana do mês de janeiro) e demais festas como Natal, Pentecostes e a celebração da Páscoa eram momentos de encontros e interação entre as pessoas - além das novenas e rezas no campo religioso. Festas familiares como batizados, casamentos, etc. também agitavam a pequena comunidade. Havia também a Sociedade de Cantores Concórda que promovia bailes, além dos conjuntos musicais que existiram tradicionalmente na história de Felipe Essig (CONRAD, 2002, p. 13). Aparentemente "inofensivas", estes momentos solidificaram a tradição comunitária da picada e prepararam os ingredientes da cooperação.

E assim a comunidade parece ter surgido como o motor do desenvolvimento e viabilidade econômica de muitas picadas teuto-brasileiras. Não se está repetindo o discurso apologético do colono idealizado, sua estrutura social igualitária e a sua abnegação diante do seu próximo. Os indivíduos cooperavam porque a ausência de infraestrutura e de efetividade do poder público (em maior ou menor grau) criou uma situação que teve de ser resolvida através do repertório cultural destes indivíduos. A picada teuto-brasileira é o nome recebido por essa comunidade humana cercada por vários riscos. E o fato dela ser cooperativa não afasta o conflito e as relações de poder existentes em seu âmago, pois mesmo nas situações de dissenso, os cidadãos da picada teuto-brasileira consideravam "o domínio público algo mais do que um campo de batalha para a afirmação do interesse pessoal" (PUTNAM, 2006, p. 102).

Viver em comunidade através da cooperação atendia primeiramente os interesses individuais, e por isso se pode explicar a agilidade e o frenesi em que as estruturas comunitárias foram criadas. Interessava aos colonos contar com uma estrutura de apoio e coordenação às suas atividades e projetos pessoais. Para que isso pudesse ocorrer, sempre haveria de existir na mente dos colonos uma possibilidade de prever o comportamento de seu vizinho ou de outro morador. E é nesse sentido que o capital social, por meio do atributo de confiança, pôde criar uma experiência social nova no Brasil.

\section{Referências}

BLICKLE, Peter. From the communal Reformation to the revolution of the common man. Leiden: Brill, 1998.

BRAKENSIEK, Stefan: Agrarreform und ländliche Gesellschaft: Die Privatisierung der Marken in Nordwestdeutschland, 1750-1850. Paderborn: Ferdinand Schöningh, 1991.

CONRAD, Paulo Francisco. História da colonização da comunidade de Picada Felipe Essig e características da agricultura familiar ali desenvolvida. Monografia (Especialização). Curso de Pós-Graduação em Desenvolvimento, Agricultura e Sociedade, UFRRJ, Seropédica, RJ, 2002.

CUNHA, Jorge Luís. Imigração e colonização alemã. In: BOEIRA, Nelson et al (orgs.) Império. Passo Fundo: Ed. Méritos, v. 2, 2006, p. 279300.

DACANAL, José H. A imigração e a história do Rio Grande do Sul. In: DACANAL, José Hildebrando (Org.). RS: Imigração e colonização. 2. ed. Porto Alegre: Mercado Aberto, 1992.

DICKIE, Maria A. Schmidt. O movimento Mucker, o demônio, a irracionalidade e o espírito. In: BOEIRA, Nelson et al (orgs.) Império. Passo Fundo: Ed. Méritos, v. 2, 2006, 337-350.

DREHER, Martin. Os 180 anos da imigração alemã. In: ARENDT, Isabel Cristina; WITT, Marcos Antônio. História, cultura e memória: 180 anos de imigração alemã: Teutônia e Westfália/RS. São Leopoldo: Oikos, 2005, p. 11-31.

DREHER, Martin: As religiões. In: Piccolo, Helga Iracema Landgraf et al (Orgs.): Império. Passo Fundo: Méritos 2006, p. 321-336.

DREHER, Martin. Breve história do ensino privado gaúcho. São Leopoldo: Oikos, 2008.

EDDIE, S. A. Freedom's price: Serfdom, subjection, and reform in Prussia, 1648-1848. Oxford: Oxford University Press, 2013.

GANS, Magda R. Presença teuta em Porto Alegre no século XIX (1850-1889). Porto Alegre, 2004.

Instituto Brasileiro de Geografia e Estatística. Disponível em: http://www.ibge.gov.br/cidadesat/painel/painel. 
php?codmun=432162\#>. Acesso em: 23 fev. 2017.

KREUTZ, Marcos Rogério. O Contexto Ambiental e as primeiras ocupações humanas no Vale do Taquari - Rio Grande do Sul. Dissertação (Mestrado em Ambiente e Desenvolvimento) Centro Universitário Univates, Lajeado, 2008.

MÜHLEN, Caroline von. Réus e vítimas: criminalidade, justiça e cotidiano em uma região de imigração alemã (São Leopoldo, 1846-1871). Tese. Programa de Pósgraduação em História PUCRS, 2017.

MÜLLER, Armindo Laudário. Crônica da paróquia evangélica de Marques de Souza. Lajeado [s.n], 1998.

PUTNAM, Robert. Comunidade e democracia: a experiência da Itália moderna. 5. ed. Rio de Janeiro: Editora FGV, 2006.

RADÜNZ, Roberto. Deutschum e italianità: uma introdução à historiografia comparada no Sul do Brasil. In: RADÜNZ, Roberto; SLOMP, Loraine (Orgs.). Imigração e cultura. Caxias do Sul: Educs, 2007, p. 117-132.

ROCHE, Jean. A colonização alemã e o Rio Grande do Sul. Porto Alegre: Globo, 1969.

SCHNEIDER, Karl Heinz. Geschichte der Bauernbefreiung. Stuttgart: Reclam, 2010.

SEYFERTH, Giralda. A colonização alemã no vale do Itajaí-Mirim: um estudo de desenvolvimento econômico. Brusque, SC: Movimento, 1974.

TRAMONTINI, Marcos Justo. A organização social dos imigrantes: A colônia de São Leopoldo na fase pioneira 1824-1850. São Leopoldo: Editora Unisinos, 2003.

VOGT, Olgário Paulo. A colonização alemã no Rio Grande do Sul e o capital social. Santa Cruz do Sul, RS: Unisc, 2006.

WEIMER, Günter. Arquitetura popular dos imigrantes: um estudo comparativo. In: RIBEIRO, Cleodes Maria Piazza; POZENATO, Jose Clemente (Orgs). Cultura, imigração e memória: percursos e horizontes. Caxias do Sul: Educs, 2004, p. 109-123.

WITT, Marcos Antônio. Em busca de um lugar ao sol: estratégias políticas (Imigração alemã-Rio Grande do Sul-século XIX). São Leopoldo: Oikos, 2008. 